\title{
Stat3-dependent acute Rantes production in vascular smooth muscle cells modulates inflammation following arterial injury in mice
}

\author{
Jason C. Kovacic, ${ }^{1}$ Rohit Gupta, ${ }^{1}$ Angela C. Lee, ${ }^{1}$ Mingchao Ma, ${ }^{1}$ Fang Fang, ${ }^{1}$ \\ Claire N. Tolbert, ${ }^{1}$ Avram D. Walts, ${ }^{1}$ Leilani E. Beltran, ${ }^{1}$ Hong San, ${ }^{2}$ Guibin Chen, ${ }^{1}$ \\ Cynthia St. Hilaire, ${ }^{1}$ and Manfred Boehm ${ }^{1}$
} ${ }^{1}$ Translational Medicine Branch, National Heart, Lung, and Blood Institute, NIH, Bethesda, Maryland, USA. ${ }^{2}$ Genome Technology Branch,
National Human Genome Research Institute, NIH, Bethesda, Maryland, USA.

\begin{abstract}
Inflammation is a key component of arterial injury, with VSMC proliferation and neointimal formation serving as the final outcomes of this process. However, the acute events transpiring immediately after arterial injury that establish the blueprint for this inflammatory program are largely unknown. We therefore studied these events in mice and found that immediately following arterial injury, medial VSMCs upregulated Rantes in an acute manner dependent on Stat 3 and NF- $\kappa B$ ( 665 subunit). This led to early $T$ cell and macrophage recruitment, processes also under the regulation of the cyclin-dependent kinase inhibitor $\mathrm{p}^{21 \mathrm{Cip} 1}$. Unique to VSMCs, Rantes production was initiated by Tnf- $\alpha$, but not by Il-6/gp130. This Rantes production was dependent on the binding of a $\mathrm{p} 65 /$ Stat 3 complex to NF- $\mathrm{KB}$-binding sites within the Rantes promoter, with shRNA knockdown of either Stat3 or p65 markedly attenuating Rantes production. In vivo, acute NF- $K B$ and Stat3 activation in medial VSMCs was identified, with acute Rantes production after injury substantially reduced in $\mathrm{Tnfa}^{-/-}$mice compared with controls. Finally, we generated mice with SMC-specific conditional Stat 3 deficiency and confirmed the Stat 3 dependence of acute Rantes production by VSMCs. Together, these observations unify inflammatory events after vascular injury, demonstrating that VSMCs orchestrate the arterial inflammatory response program via acute Rantes production and subsequent inflammatory cell recruitment.
\end{abstract}

\section{Introduction}

Inflammation, cytokine production, and VSMC proliferation are pivotal aspects of arterial wound repair $(1,2)$. Unfortunately, this process often culminates in excessive neointimal formation and decreased luminal diameter $(1,2)$, a pathology associated with adverse clinical outcomes (3). Although early inflammation is known to modulate this process (4), given the clinical implications of reduced luminal diameter (3), investigators have generally chosen to focus on late events surrounding neointimal formation and VSMC proliferation. Conversely, significantly less attention has been paid to the acute immune responses that orchestrate the initial vascular inflammatory response program and establish the blueprint for vascular repair.

An additional key component of this process is the recruitment of macrophages and $T$ cells $(1,2,5)$. While certain regulatory subtypes differ in their responses $(6,7)$, macrophage and $T$ cell recruitment typically leads to enhanced inflammation and neointimal formation as well as reduced luminal patency $(1,2,5,8-11)$. A complex network of cytokines, chemokines, and their receptors is known to regulate recruitment of these cells $(2,5,10-14)$. However, surprisingly little data are available regarding acute local cytokine/chemokine production or early vascular inflammatory cell infiltration.

We recently identified increased $\mathrm{T}$ cell and macrophage infiltration and enhanced neointimal formation 1 and 2 weeks after arterial injury in $p 21^{-/-}$compared with WT mice (2). These findings were related to enhanced Stat 3 activity in $p 21^{-/-}$VSMCs (2) and are consistent with reports indicating that $\mathrm{p}^{2} 1^{\mathrm{Cip} 1}$ inhibits Stat3-mediated

Conflict of interest: The authors have declared that no conflict of interest exists. Citation for this article: J. Clin. Invest. 120:303-314 (2010). doi:10.1172/JCI40364. gene transcription (15) and that Stat 3 is an important inflammatory mediator $(16,17)$. Of relevance, at least in epithelial cells, Stat3 may form a transcription complex with NF-кB, another key inflammatory mediator (18), leading to the expression of Rantes (17).

Rantes, otherwise known as Ccl5, is a chemokine produced in response to stimulation by cytokines such as Il-6 (17) and/or Tnf- $\alpha$ (19) and may be secreted by a variety of cells, including VSMCs $(14,20)$, epithelial cells (17), T cells (21), macrophages (22), and also platelets $(14,23)$. Rantes exerts a multitude of generally proinflammatory effects and is of importance in $\mathrm{T}$ cell and monocyte chemoattraction (24), T cell proliferation, and the delayed-type hypersensitivity response (25). Correspondingly, Rantes may be involved in the pathobiology of several clinical inflammatory conditions, such as cardiac allograft vasculopathy (21), atherosclerosis $(26,27)$, asthma (28), and rheumatoid arthritis (29).

While Rantes is clearly implicated in the vascular response to injury, the majority of prior studies considered only long-term actions and effects over the duration of vascular healing $(14,20,23,27,30$, 31 ). The role of Rantes in the acute phase of vascular injury and the potential interrelationships of $\mathrm{p}^{21^{\text {Cip } 1}}$ and Rantes signaling are virtually unexplored. Here, we characterize early events surrounding initiation of the vascular inflammatory response program, which is notable for a striking upregulation of Rantes production by VSMCs. Synthesis of Rantes by VSMCs occurs in response to Tnf- $\alpha$ and down-

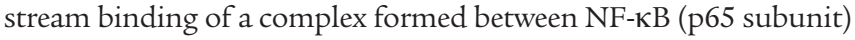
and Stat 3 to the Rantes promoter, which is restrained by $\mathrm{p} 21^{\text {Cip } 1}$ and independent of the Il-6/gp130 pathway. This NF-кB/Stat3/Rantes signaling pathway orchestrates early $\mathrm{T}$ cell and macrophage recruitment, thereby identifying VSMCs as exerting an immune-modulating role during the acute response to vascular injury. 

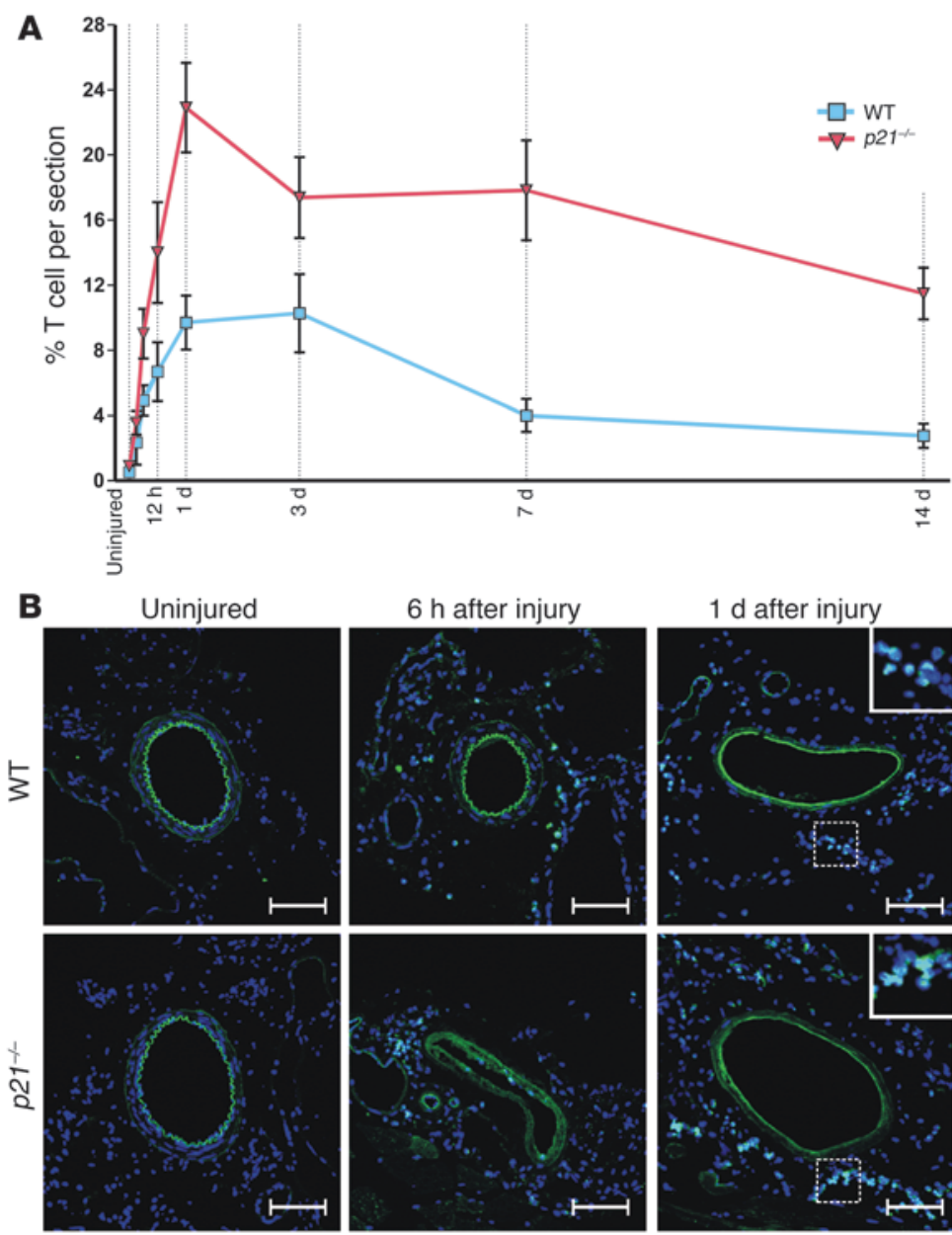

Figure 1

$\mathrm{CD}^{+} \mathrm{T}$ cell infiltration following arterial wire injury. (A) Relative $\mathrm{CD}^{+} \mathrm{T}$ cell infiltration in WT and $p 21^{-/-}$mice. Data are shown as mean \pm SEM. (B) Representative corresponding confocal microscopic images of femoral artery sections showing $\mathrm{CD}^{+} \mathrm{T}$ cells (green) in uninjured vessels and at 6 hours and 1 day following arterial wire injury, with the dashed square indicating an area of higher magnification shown in the upper-right corner for the 1-day images. Width of inset square: $70 \mu \mathrm{m}$. Nuclei (blue) were stained with DAPI. Arterial elastic laminae are visible in green due to autofluorescence. Scale bars: $100 \mu \mathrm{m}$.

of infiltrating $\mathrm{CD}^{+} \mathrm{T}$ cells and $\mathrm{CD} 115^{+}$macrophages were consistently higher in $p 21^{-/-}$versus WT mice after injury (Supplemental Figure 4, A and B), unlike T cells, the percentage of macrophages at both 3 and 14 days after injury was identical in WT and $p 21^{-/-}$mice (Supplemental Figure 2). Consistent with prior reports (34, 35), we also identified a marked loss of medial VSMCs following arterial injury (Supplemental Figure 4C). To further confirm these findings, we examined CD3 and CD115 mRNA levels in femoral artery sections harvested uninjured or after vascular injury. Consistent with our other data (above), we identified a progressive and

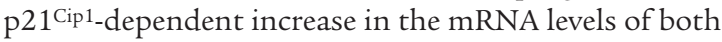
genes following vascular injury (Supplemental Figure 5). Collectively, these data demonstrate that arterial injury results in a marked acute and p21 ${ }^{\text {Cip } 1 \text {-regulated local }}$ $\mathrm{CD}^{+} \mathrm{T}$ cell infiltration, with a more delayed infiltration observed for $\mathrm{CD} 115^{+}$macrophages.

Acute Rantes, $p 21^{\text {Cip } 1}$, and Stat 3 expression by VSMCs after arterial injury. Based on the above observations, we examined local vascular expression of Rantes, a known $\mathrm{T}$ cell and macrophage chemoattractant (24), revealing acute

\section{Results}

Acute T cell and macrophage recruitment following arterial wire injury. We examined inflammatory cell recruitment after femoral artery injury in WT mice and identified an acute infiltration of macrophages and $\mathrm{T}$ cells. From baseline (uninjured) to 1 day after injury, $\mathrm{CD}^{+}$ $\mathrm{T}$ cells increased approximately 20 -fold from $0.5 \% \pm 0.3 \%(n=9)$ to $9.7 \% \pm 1.7 \%(n=10)$ of all vessel-associated cells $(P<0.0001)$ (Figure 1 and Supplemental Figure 1; supplemental material available online with this article; doi:10.1172/JCI40364DS1). Relative $\mathrm{T}$ cell infiltration plateaued 1 to 3 days after injury and subsequently declined, decreasing from $10.3 \% \pm 2.4 \%(n=8)$ at 3 days to $4.0 \% \pm 1.0 \%(n=10)$ by 7 days after injury $(P<0.05)$ (Figure 1$)$. In contrast, acute $\mathrm{CD} 115^{+}$macrophage infiltration was somewhat less pronounced, increasing from $4.7 \% \pm 0.7 \%(n=8)$ to $8.5 \% \pm 1.1 \%$ $(n=10)$ (uninjured versus 1 day after injury; $P<0.05)$. However, macrophage recruitment was ongoing, with relative infiltration peaking 3 days after injury in WT mice at $29.6 \% \pm 4.3 \%(n=9)$ (Supplemental Figures 2 and 3). To validate these observations, we employed a second animal model, utilizing mice with genetic p21 Cip1 deletion, which are known to exhibit enhanced inflammation following arterial injury $(2,32,33)$. We found that $p 21^{-1-}$ mice displayed augmented early $\mathrm{CD}^{+} \mathrm{T}$ cell recruitment, with $\mathrm{CD}^{+}$ $\mathrm{T}$ cells representing $22.9 \% \pm 2.6 \%(n=7)$ of all vessel-associated cells 1 day after injury in $p 21^{-/-}$mice $\left(p 21^{-/-}\right.$versus WT; $\left.P<0.001\right)$ (Figure 1 and Supplemental Figure 1). Although absolute numbers local upregulation of Rantes mRNA expression within 6 hours of injury (Figure $2 \mathrm{~A}$ ). Consistent with the enhanced $p 21^{-/-}$vascular inflammatory response $(2,32,33)$ and pattern of $\mathrm{CD}^{+}$cell infiltration, local Rantes expression 3 and 6 hours after injury was greater in $p 21^{-/-}$than WT mice. Although local vascular Rantes levels also trended higher in $p 21^{-/-}$versus WT mice at 12 hours, 1 day, and 3 (Supplemental Figure 4C), these differences were not significant (Figure 2A). Local expression levels of other potential acute $\mathrm{T}$ cell chemoattractants after vascular injury, while at times increased, were less marked than that of Rantes and not consistent with the pattern of early $\mathrm{T}$ cell infiltration (Supplemental Figure 6).

Local vascular mRNA expression of $p 21^{\text {Cip } 1}$ and Stat 3 also increased acutely after injury (Figure 2A). Interestingly, the pattern and time course of increased $p 21^{\text {Cip } 1}$ expression corresponded to that of both Rantes and Stat3, reinforcing our finding that Rantes expression is greater in $p 21^{-/-}$than WT mice, but also suggesting that $\mathrm{p} 21^{\mathrm{Cip} 1}$ may modulate Stat 3 transcription. Indeed, including at 6 hours after injury, Stat 3 mRNA expression in injured vessels was generally 1 - to 4 -fold higher in $p 21^{-/-}$than WT mice (Figure $2 \mathrm{~A}$ ). We further validated these in vivo data by examining Rantes and Stat3 levels in vitro in VSMCs. These studies confirmed increased Rantes mRNA (Supplemental Figure 7A) and protein (Supplemental Figure 7B) expression in $p 21^{-1-}$ versus WT VSMCs. Similarly, Stat3 mRNA expression was also greater in $p 21^{-1^{-}}$verdays after injury, perhaps related to concurrent medial VSMC loss 
A
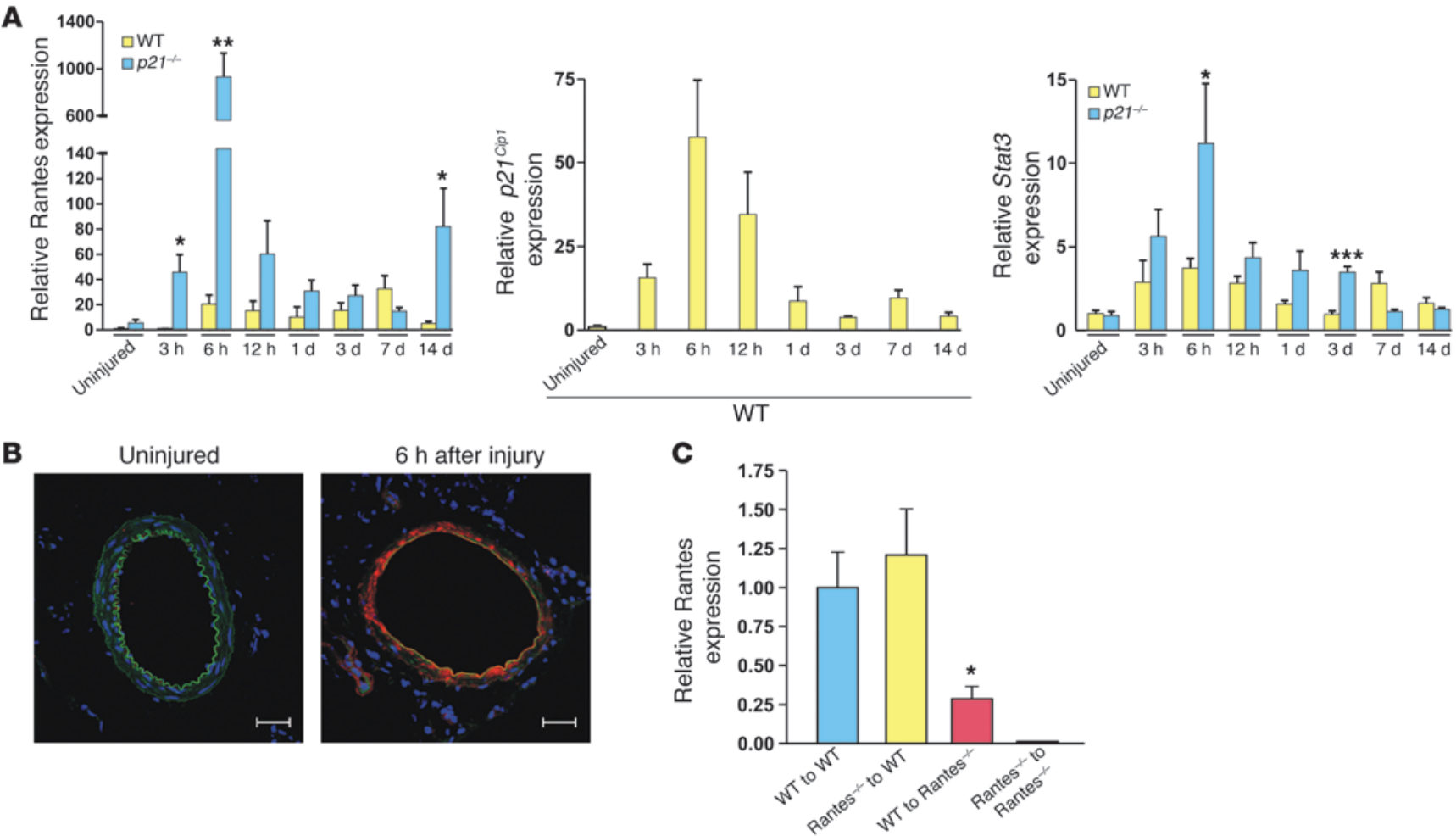

Figure 2

Rantes production is acutely upregulated following arterial injury and produced locally by medial VSMCs. (A) Local Rantes (left panel), p21cip1 (middle panel), and Stat3 (right panel) mRNA expression after arterial injury by qRT-PCR. Comparisons shown are WT versus $p 21^{-/-}$at each respective time point for Rantes and Stat3, with $p 21$ cip1 expression assessed in WT mice only. ${ }^{\star} P<0.05 ;{ }^{\star \star} P<0.01 ;{ }^{\star \star \star} P<0.0001$. Also, in WT mice from baseline (uninjured) to 6 hours after injury, local vascular Rantes mRNA expression increased 21 -fold $(n=5$ both groups; $P<0.05$ ); p21 ${ }^{\text {cip } 1}$ mRNA expression increased 58 -fold $(n=10$ at baseline, $n=7$ at 6 hours; $P<0.005)$; and Stat3 mRNA expression increased 3.5 -fold ( $n=7$ at baseline, $n=12$ at 6 hours; $P<0.001$ ). (B) Representative confocal microscopic images of Rantes immunofluorescence staining of femoral artery sections from WT mice at baseline (uninjured) and 6 hours after injury. Rantes is shown in red, nuclei in blue (DAPI). Arterial elastic laminae are visible in green due to autofluorescence. Scale bars: $100 \mu \mathrm{m}$. (C) BM-transplanted mice were used to localize Rantes production 6 hours after arterial injury. By ANOVA (overall $P=0.0045$ ), Rantes ${ }^{-1}$ mice reconstituted with WT BM (WT to Rantes $\left.{ }^{-1-} ; n=4\right)$ had decreased femoral artery Rantes mRNA expression in comparison with WT mice reconstituted with either WT (WT to WT, $n=6$; ${ }^{*} P<0.05$ versus WT to Rantes $^{-/}$) or Rantes ${ }^{-1}$ BM (Rantes ${ }^{-/}$to WT, $n=5 ;{ }^{*} P<0.05$ versus WT to Rantes ${ }^{-1}$ ). Data are shown as mean + SEM.

sus WT VSMCs (Supplemental Figure 7C), with the magnitude of increased Stat 3 expression in $p 21^{-/-}$versus WT $(\sim 2.5$-fold $)$ consistent between our in vitro and in vivo studies.

Confocal immunofluorescence microscopy was used to localize the site of acute Rantes production. While occasional adventitial cells stained positive for Rantes, overwhelmingly, the greatest positive Rantes staining was in medial VSMCs (Figure 2B). We verified that increased Rantes mRNA levels after injury were due to enhanced local production, and not infiltrating BM cells, by reciprocal BM transplantation between WT and Rantes ${ }^{-/-}$mice. These experiments confirmed that more than $70 \%$ of Rantes in vessels 6 hours after injury was locally derived, while less than 30\% potentially arose from BM-derived cells (Figure 2C).

Vascular Rantes expression regulates inflammatory cell infiltration and neointimal formation following arterial injury. To investigate the functional role of acute Rantes production by medial VSMCs, we examined inflammatory cell infiltration at 1 day after injury in WT and Rantes $^{-/-}$mice reconstituted with WT BM (WT to WT and WT to Rantes $^{-/}$, respectively). As expected, $\mathrm{CD}^{+} \mathrm{T}$ cell and $\mathrm{CD} 115^{+}$macrophage infiltration 1 day after injury were similar between WT to
WT mice (Figure 3, A and B) and our original experiments using WT mice without BM transplantation (Figure 1A and Supplemental Figure 2A). However, compared with WT to WT, WT to Rantes ${ }^{-/}$ mice displayed a marked reduction in $\mathrm{CD}^{+} \mathrm{T}$ cell and $\mathrm{CD} 115^{+}$macrophage infiltration (Figure 3, A and B, and Supplemental Figure 8), indicating that acute local Rantes production regulates early $\mathrm{T}$ cell and macrophage recruitment following arterial injury.

Systemic Rantes antagonism is associated with reduced neointimal formation after vascular injury (14). However, the relative contributions of local vascular Rantes production versus BM cell- and platelet-derived Rantes to augmented neointimal formation are unknown. Therefore, WT to WT and WT to Rantes ${ }^{-/-}$mice were subjected to arterial wire injury, and neointimal formation was assessed after 3 weeks. Consistent with the concept that local Rantes production modulates the vascular inflammatory response program, neointimal formation in WT to Rantes ${ }^{-/}$mice was significantly reduced compared with that in WT to WT mice (Figure 3, C and D).

$N F-\kappa B$ and Stat 3 interact to modulate Rantes transcriptional activity in VSMCs. We sought to identify early $\mathrm{p} 65$ and Stat 3 activation in medial VSMCs - transcription factors known to regulate Rantes 
A
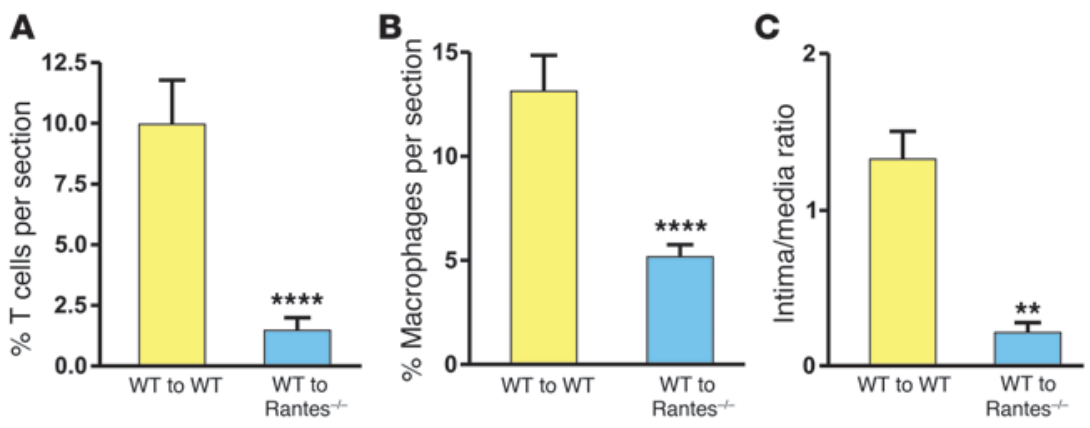

D

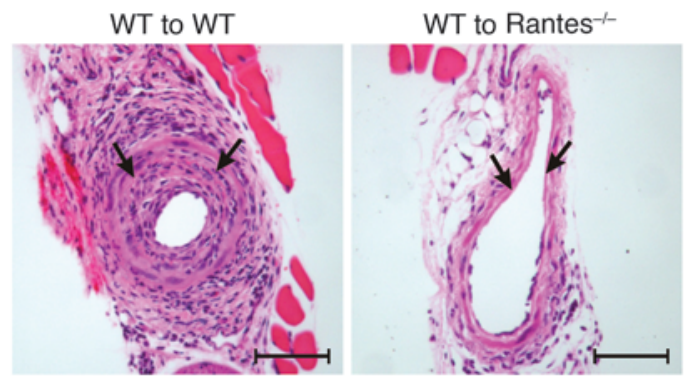

Figure 3

Local vascular Rantes production regulates early $\mathrm{CD}^{+} \mathrm{T}$ cell and $\mathrm{CD} 115^{+}$macrophage infiltration and late neointimal formation following arterial injury. (A) WT to WT and WT to Rantes ${ }^{-/}$mice underwent arterial injury, and cell infiltration was assessed at 1 day. Relative $\mathrm{CD}^{+} \mathrm{T}$ cell infiltration was reduced in WT to Rantes ${ }^{-/-}$mice compared with WT to WT mice ( $n=6$ for WT to WT, $n=9$ for WT to Rantes $\left.{ }^{-1-;}{ }^{* * *} P<0.0005\right)$. (B) Relative CD115+ macrophage infiltration was reduced 1 day after arterial injury in WT to Rantes ${ }^{-/}$mice compared with WT to WT mice ( $n=7$ for WT to WT, $n=9$ for WT to Rantes $\left.{ }^{-/-} ;{ }^{* * *} P<0.0005\right)$. (C) Neointimal formation at 3 weeks after arterial injury, as assessed by intima/media ratio, was decreased in femoral vessels from WT to Rantes ${ }^{-/}$ as compared with WT to WT mice ( $n=9$ for WT to WT, $n=8$ for WT to Rantes ${ }^{--;}$; $\left.{ }^{* *} P<0.001\right)$. Data are shown as mean + SEM. (D) Representative cross sections of femoral arteries from WT to WT and WT to Rantes mice at 3 weeks after arterial wire injury (stained with H\&E). Arrows indicate the internal elastic lamina. Scale bars: $100 \mu \mathrm{m}$. production $(17,36)$. In uninjured vessels, consistent with prior reports $(37,38)$, we identified $\mathrm{p} 65$ and Stat 3 cytoplasmic staining in endothelial cells. However, p65, Stat3, and phosphorylated Stat3 (p-Stat3) were not detectable in medial VSMCs from uninjured vessels (Figure 4). Within hours of arterial injury (and endothelial denudation), endothelial staining for these proteins was absent, but robust perinuclear and nuclear staining for p65, Stat3, and p-Stat3 were apparent in the medial VSMC layer (Figure 4), indicating early NF- $\mathrm{\kappa B}$ and Stat 3 activation in VSMCs and suggesting these transcription factors may play a role in acute Rantes production.

We then interrogated the murine Rantes promoter and identified 2 likely NF-кB-binding sites. These sites spanned -372 to

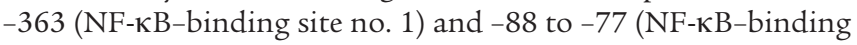
site no. 2) of the Rantes promoter, with at least 1 site (no. 2) previously identified and validated in 3T3 fibroblasts (36). We mutated both putative NF- $\mathrm{BB}$-binding sites in a luciferase plasmid containing the murine Rantes promoter and individually transfected mutated (M1 and M2) and nonmutated luciferase control (Co) constructs into WT and p21-/- VSMCs. In Co VSMCs, consistent with Rantes expression and secretion, Rantes promoter activity was increased in $p 21^{-/-}$versus WT VSMCs (Figure $5 \mathrm{~A}$ ). Furthermore, mutation of either putative NF- $\mathrm{KB}$-binding site markedly reduced Rantes promoter activity (Figure 5A).

\section{Figure 4}

Stat3 and p65 are acutely activated following arterial injury in medial VSMCs. Representative confocal images of immunofluorescence-stained femoral artery sections from WT mice at baseline (uninjured) and acutely after injury for p65 (6 hours after injury), Stat3 (6 hours after injury), and p-Stat3 (Tyr705) (3 hours after injury). p65, Stat3, and p-Stat3 are shown in red, nuclei in blue (DAPI). Arterial elastic laminae are visible in green due to autofluorescence. Scale bars: $20 \mu \mathrm{m}$.
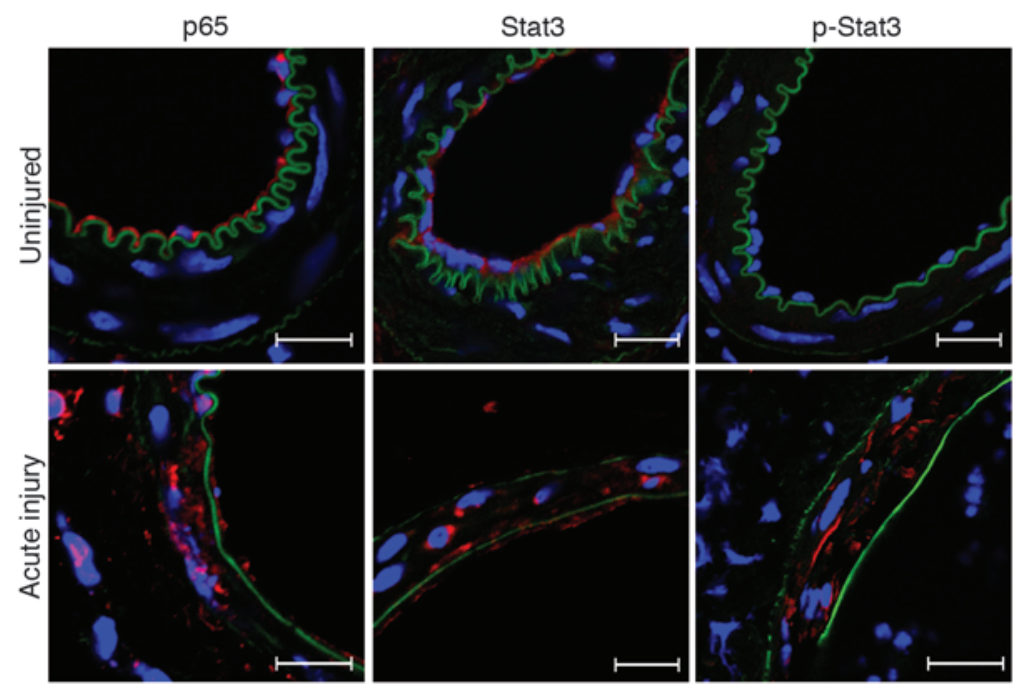
A

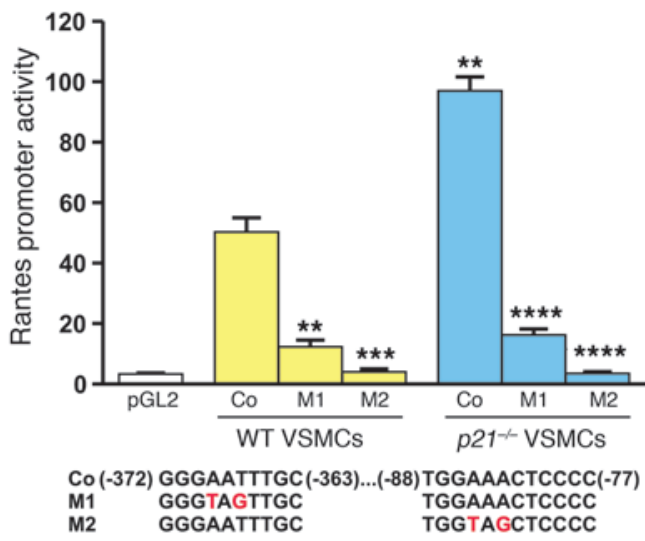

B
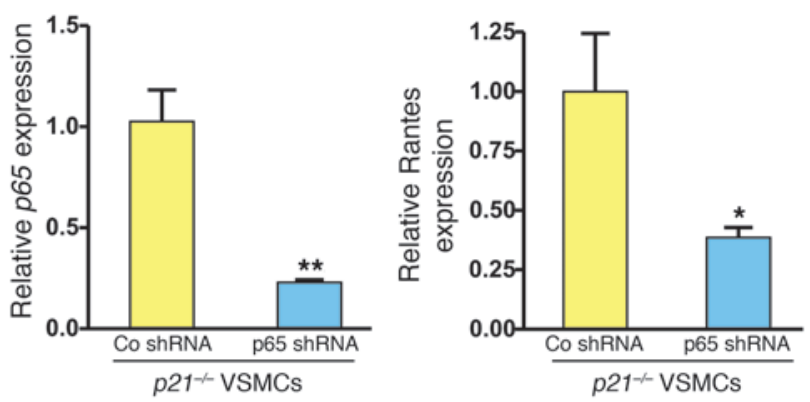

C

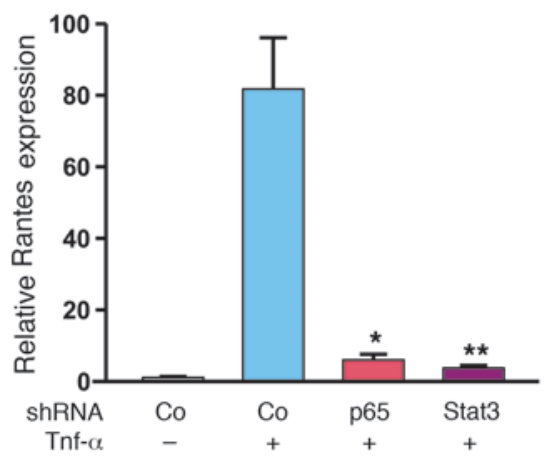

D

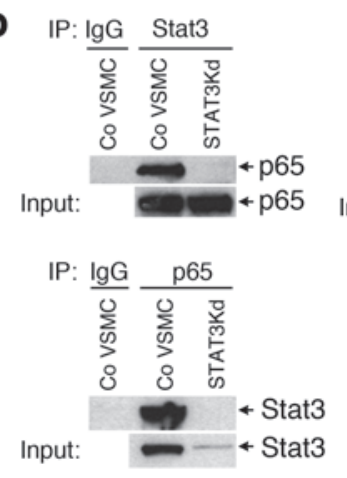

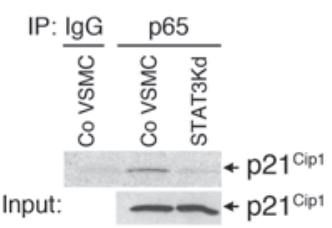

p21

\section{Figure 5}

Stat3 and p65 coassociate and regulate Rantes expression in VSMCs. (A) VSMCs were transfected with reporter plasmids containing the native Rantes promoter (Co) or mutated plasmids (M1 or M2) designed to abolish putative NF-kB-binding site activity. Location and sequence of putative NF-кB-binding sites and mutations are indicated. Comparisons are Co $p 21^{-/-}$versus Co WT, or M1 or M2 versus Co for WT and $p 21^{-1-}$. pGL2 indicates WT VSMCs transfected with pGL2 plasmid containing no promoter. $n=3$ for all groups; ${ }^{* *} P<0.005$, ${ }^{* * *} P<0.001$, ${ }^{* * * \star} P<0.0001$. (B) shRNA p65Kd in $p 21 \mathrm{VSMCs}$ reduced mRNA expression of $p 65$ (left panel, $n=3$ both groups; ${ }^{* *} P<0.01$ ) and Rantes (right panel, $n=4$ both groups; $\left.{ }^{*} P<0.05\right)$ compared with Co shRNA. (C) Tnf- $\alpha$ treatment for 4 hours increased Rantes mRNA expression in WT Co VSMCs $(n=6$ for unstimulated, $n=7$ for stimulated; $P<0.0005$ ), while p65Kd and Stat3Kd VSMCs exhibited attenuated Tnf- $\alpha$-induced Rantes mRNA expression compared with Tnf- $\alpha$-treated Co VSMCs (p65Kd: $n=3,{ }^{*} P<0.05$; Stat3Kd: $n=4,{ }^{* \star} P<0.005$ ). Data are shown as mean + SEM. (D) IP followed by WB in WT Co and Stat3Kd VSMCs (input protein levels as indicated). IP with anti-Stat3 then WB with anti-p65 (upper left) and IP with anti-p65 then WB with anti-Stat3 (lower left) revealed coassociation of p65 and Stat3. IP with anti-p65 then WB with anti-p21Cip1 (upper right) revealed coassociation of $\mathrm{p} 65$ with $\mathrm{p} 21^{\text {Cip } 1}$, which was virtually abolished in Stat3Kd VSMCs.

To explore the possibility that coassociation of $\mathrm{p} 65$, Stat 3 , and/ or $\mathrm{p}^{2} 1^{\mathrm{Cip} 1}$ plays a role in these findings, IP followed by Western blotting (WB) was performed in VSMCs. These experiments identified a p65/Stat 3 complex and also showed that $\mathrm{p} 65$ and $\mathrm{p} 21^{\mathrm{Cip} 1}$ coassociate in VSMCs (Figure 5D). We also detected reduced p65/ p21 Cip1 complex levels in Stat3Kd VSMCs, suggesting that Stat3 supports the $\mathrm{p} 65 / \mathrm{p} 21^{\text {Cip } 1}$ interaction (Figure 5D).

We further investigated the relationship between Stat 3 and p65/NF- $\mathrm{kB}$, studying in detail their combinatorial binding at the putative NF- $\mathrm{KB}$-binding sites in the Rantes promoter using quantitative ChIP with WT Co and Stat 3 Kd VSMCs. Tnf- $\alpha$-stimulated Co VSMCs exhibited enhanced binding of both Stat 3 and p65 at NF-кB-binding site no. 1 of the Rantes promoter (Figure 6, A and B). In contrast, Tnf- $\alpha$-stimulated Stat 3 Kd VSMCs showed markedly attenuated $\mathrm{p} 65$ binding at NF-KB-binding site no. 1 of the Rantes promoter (Figure 6C), indicating that Stat 3 is required for p 65 binding at this site. We also observed enhanced Stat 3 binding to NF-кB-binding site no. 2 following Tnf- $\alpha$ stimulation (Supplemental Figure 10A). While p65 binding was also enhanced at
NF-кB-binding site no. 2 with Tnf- $\alpha$ stimulation, this was somewhat more modest than p65 binding at site no. 1 (Supplemental Figure 10B). Although not as robust as the data for site no. 1, Tnf- $\alpha$-stimulated Stat3Kd VSMCs nonetheless displayed reduced p 65 binding at NF-KB-binding site no. 2 of the Rantes promoter (Supplemental Figure 10C). Taken as a whole, these data indicate early p 65 and Stat 3 activation after arterial injury and show that the combined presence of these transcription factors, likely coassociated as a complex, is required for their effective binding to NF- $\kappa \mathrm{B}$-binding sites of the Rantes promoter in VSMCs.

Tnf- $\alpha$, but not Il-6, stimulates Rantes transcription in VSMCs. We investigated the upstream pathways leading to Rantes expression in VSMCs by evaluating the effect of treatment with Tnf- $\alpha$ versus Il-6, both potential activators of Stat 3 and/or NF-кB. Tnf- $\alpha$ treatment led to a time-dependent increase in Rantes transcription, with 8 hours of Tnf- $\alpha$ exposure resulting in a greater than 450-fold increase in Rantes mRNA expression (Figure 7A). Surprisingly, Il-6 treatment for up to 8 hours (Figure 7B) or even 1 day (data not shown) did not appreciably alter Rantes mRNA levels. 
A

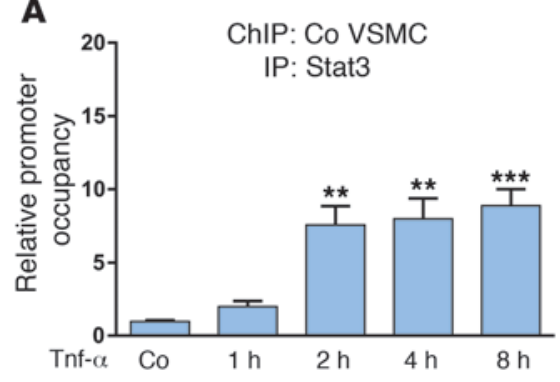

B

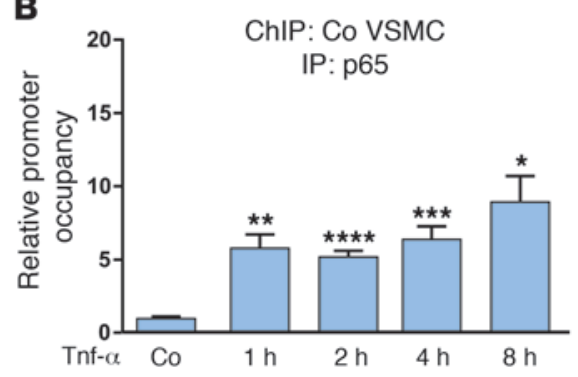

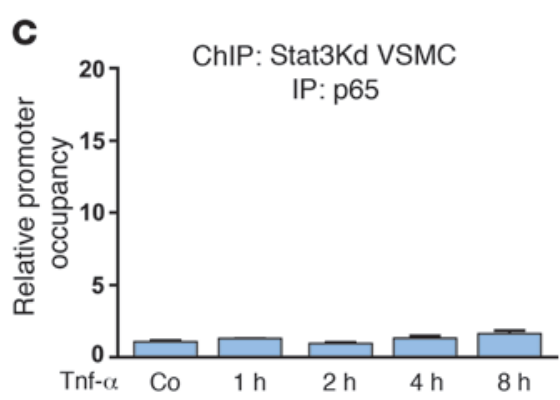

Figure 6

Interdependent Stat3 and p65 binding to NF-кB-binding site no. 1 of the Rantes promoter. (A) ChIP of WT Co VSMCs with IP using anti-Stat3 antibody showing Stat3 binding to NF-kB-binding site no. 1 of the Rantes promoter without (Co) or with Tnf- $\alpha$ stimulation for $1,2,4$, or 8 hours immediately prior to protein-DNA cross-linking (Co versus 2 hours and Co versus 4 hours, ${ }^{* *} P<0.01$; Co versus 8 hours, ${ }^{* * *} P<0.005 ; n=3$ for all groups). (B) ChIP of WT Co VSMCs with IP using anti-p65 antibody showing p65 binding to NF-kB-binding site no. 1 of the Rantes promoter following Tnf- $\alpha$ stimulation (Co versus 1 hour, ${ }^{* \star} P<0.01$; Co versus 2 hours, ${ }^{* * \star *} P<0.001$; Co versus 4 hours, ${ }^{* * *} P<0.005$; Co versus 8 hours, ${ }^{*} P<0.05 ; n=3$ for all groups). (C) ChIP of WT Stat3Kd VSMCs with IP using anti-p65 antibody showing p65 binding to NF-kB-binding site no. 1 of the Rantes promoter following Tnf- $\alpha$ stimulation ( $n=3$ for all groups). Data are shown as mean + SEM.

Given this, we compared Stat 3 activation patterns in WT murine VSMCs and 3T3 fibroblasts. Il-6 treatment of VSMCs resulted in a gradual increase in p-Stat 3 . However, Tnf- $\alpha$ stimulation induced a rapid initial accumulation of $\mathrm{p}$-Stat 3 in VSMCs that waned with longer duration of Tnf- $\alpha$ treatment (Figure 7C). In contrast, Il-6 treatment of 3T3 cells caused a more robust increase in p-Stat 3 , but most notably, p-Stat3 was almost undetectable in $3 \mathrm{~T} 3$ fibroblasts until after 8 hours of Tnf- $\alpha$ treatment (Figure 7C). Therefore, while Il-6 induces Stat 3 phosphorylation, stimulation with Tnf- $\alpha$ leads to a differing pattern of Stat 3 activation, with only Tnf- $\alpha$ able to induce Rantes expression in VSMCs.

We explored the involvement of the predominant Tnf- $\alpha$ receptor, Tnf- $\alpha$ receptor 1 (Tnf- $\alpha-\mathrm{R} 1$ ), and gp130 (an Il-6 signal transducer) in these pathways. Using Tnf- $\alpha-\mathrm{R} 1-$ blocking antibody, we confirmed that Stat 3 activation in response to Tnf- $\alpha$ was at least partially mediated via ligand binding at Tnf- $\alpha-\mathrm{R} 1$ (Figure 7D). We next examined Rantes expression in VSMCs after knockdown of gp130 (gp130Kd) (Supplemental Figure 9D). Although the pattern of Rantes mRNA expression in gp130Kd VSMCs was consistent with our earlier data, we failed to detect any difference in the response to Tnf- $\alpha$ or Il- 6 stimulation between Co and gp130Kd VSMCs (Figure 7E). These data indicate that Tnf- $\alpha$-activated NF- $\kappa \mathrm{B} /$ Stat3 signaling regulates Rantes transcriptional activation in VSMCs. Although the Il-6/Stat3 pathway may regulate Rantes in other cell types (17), our data suggest that Il-6/gp130 signaling has little effect on Rantes production in VSMCs.

Vascular Rantes expression is dependent on Tnf- $\alpha$ and Stat 3 in vivo. Finally, we sought to confirm that a Tnf- $\alpha$-initiated and Stat3dependent pathway of acute Rantes production is operative in vivo. Thus, mice with genetic deletion of Tnf- $\alpha$ underwent arterial injury. Compared with vessels from WT mice, arteries from Tnfa-/mice exhibited a significant reduction in Rantes mRNA expression at 6 hours after arterial injury (Figure 8A). Next, a conditional mouse line with inducible and specific Stat 3 knockdown in smooth muscle cells (Stat 3 flffl:SM22 $\alpha$-Cre) was generated. Vascular specificity of SM $22 \alpha$-Cre for medial VSMCs was confirmed (see Methods), and although Stat 3 knockdown was VSMC-specific and quantitative real-time PCR (qRT-PCR) was of entire femoral artery samples (including adventitia and other non-VSMC tissues), we observed more than $40 \%$ total vessel knockdown of Stat 3 mRNA in induced
Stat $3^{f / f l} ; S M 22 \alpha$-Cre mice $\left(n=8\right.$ for WT, $n=6$ for Stat $3^{f / f l} ;$ SM22 $\alpha$-Cre; $P=0.05)$. Importantly, compared with vessels from WT mice, arteries from $S t a t 3^{f l / f l} ; S M 22 \alpha$-Cre mice exhibited a significant reduction in Rantes mRNA expression at 6 hours after arterial injury (Figure $8 \mathrm{~B})$. These data validate our in vitro experiments and confirm that acute local vascular Rantes production is stimulated by Tnf- $\alpha$ and modulated by downstream NF-кB/Stat3 signaling.

\section{Discussion}

Relatively little is known regarding the initiation of the vascular inflammatory program and to what extent VSMCs contribute to this process. We identified acute Rantes production by medial VSMCs following arterial injury. In VSMCs, stimulation by Tnf- $\alpha$, but not Il-6, caused Stat 3 activation and Rantes transcription - processes also under the higher-order control of p21 ${ }^{\text {Cip } 1}$. Stat 3 and p65 coassociated in VSMCs, were individually obligatory for maximal Rantes expression, and were synergistic with respect to binding at NF- $\mathrm{KB}$-binding domains of the Rantes promoter. Functionally, Tnf- $\alpha$-initiated and Stat3-dependent VSMC Rantes production dictated $\mathrm{T}$ cell and macrophage recruitment during acute vascular remodeling, while local Rantes production modulated late neointimal formation.

This work was driven by our finding of marked early macrophage and $T$ cell recruitment following arterial injury. The acute recruitment of these cells has not, to our knowledge, previously been characterized in detail following vascular injury. Nevertheless, the importance of $\mathrm{T}$ cells and macrophages during vascular wound repair is incontrovertible. Initial evidence arose from broad knockdown models, including clodronate-induced macrophage depletion (39), anti-CD11b antibody administration (8), and $\mathrm{Rag}^{-/}$mice with absence of $\mathrm{B}$ and $\mathrm{T}$ lymphocytes (1), in which depletion of macrophages/lymphocytes/neutrophils led to reduced neointimal formation. While certain regulatory subtypes retard vascular inflammation $(6,7)$, the paradigm that macrophages and $T$ cells generally enhance inflammation and neointimal formation has been reinforced by genetic deletion of key surface antigens such as P-selectin glycoprotein ligand-1 (12), CCR2 (10, 11), CXCR3 (5), and CX3CR1 (13) or the inhibition of specific chemokines including monocyte chemotactic protein-1 (Mcp-1) (11), stromal cell-derived factor-1 (Sdf-1) (2), and Rantes (14). 
A

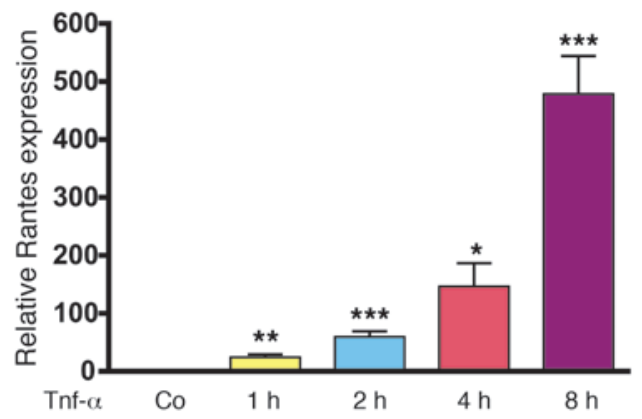

C

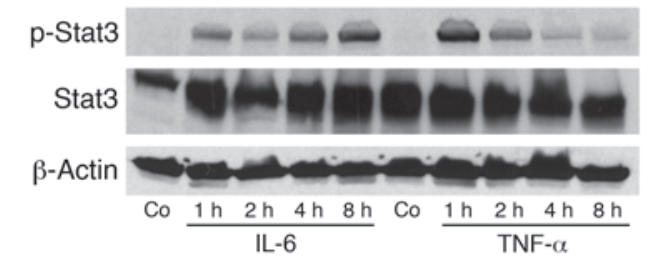

B

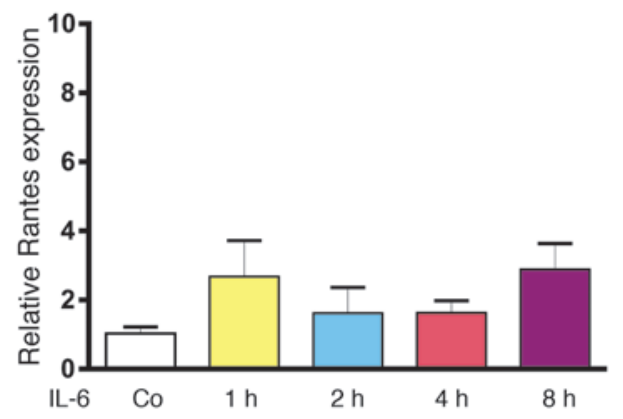

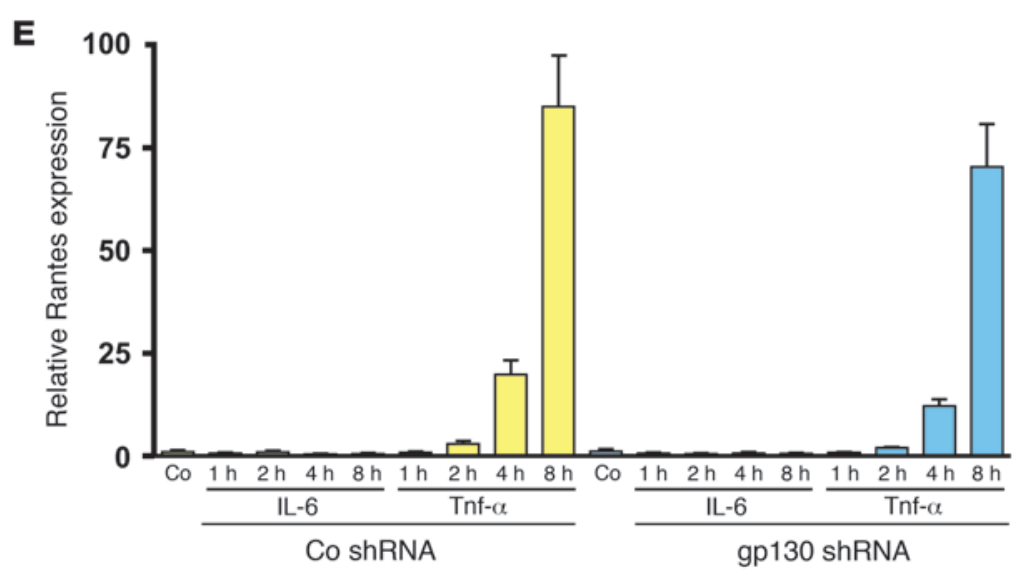

3T3 cells

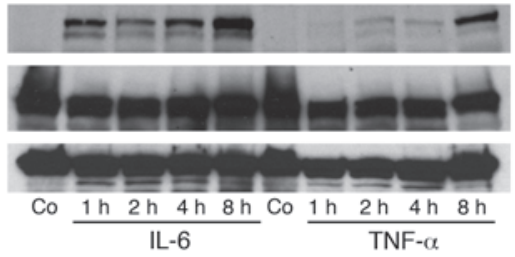

D

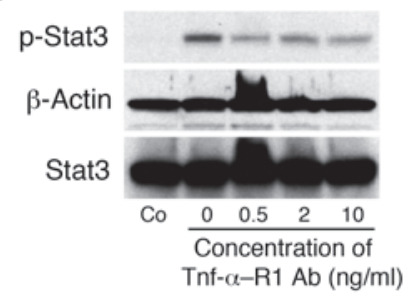

\section{Figure 7}

Tnf- $\alpha$, but not II-6/gp130, stimulates Rantes transcription in VSMCs. (A) qRT-PCR for Rantes mRNA expression in WT VSMCs without (Co) or with Tnf- $\alpha$ stimulation for 1, 2, 4, or 8 hours (Co versus 1 hour, ${ }^{* \star} P<0.01$; Co versus 2 hours, ${ }^{* \star *} P<0.005$; Co versus 4 hours, ${ }^{\star} P<0.05$; Co versus 8 hours, ${ }^{* *} P<0.005 ; n=3$ for all groups). (B) qRT-PCR for Rantes mRNA expression in WT VSMCs without (Co) or with II-6 stimulation for $1,2,4$, or 8 hours ( $n=3$ for all groups). (C) WBs for $p$-Stat3 in WT VSMCs versus 3T3 cells without (Co) or with Tnf- $\alpha$ or II-6 stimulation for 1, 2, 4, or 8 hours. Levels of Stat3 and $\beta$-actin are shown and were similar between groups. (D) WB for p-Stat3 in WT VSMCs pretreated with Tnf- $\alpha-$ R1-blocking antibody at the indicated concentrations and then stimulated with Tnf- $\alpha$. Co lane: WB using IgG on VSMCs receiving Tnf- $\alpha$ stimulation but not Tnf- $\alpha-$ R1-blocking antibody. Levels of Stat3 and $\beta$-actin are shown and were similar between groups. (E) WT Co and gp130Kd VSMCs without (Co) or with II-6 or Tnf- $\alpha$ treatment for 1, 2, 4, or 8 hours. No differences in Rantes mRNA expression were observed between cell types ( $n=3$ for all groups). Data are shown as mean + SEM.

Rantes promoter activity $(19,36)$ and transcription (40) may be stimulated by Tnf- $\alpha$ and mediated by NF- $\kappa B$ in various non-VSMC populations. However, in mammary epithelial cells, it was recently proposed that Il-6 stimulation leads to Stat 3 phosphorylation, increased concentrations of unphosphorylated Stat3, and eventually increased Rantes transcription (17). In rat-derived VSMCs, Il-6 is known to induce cell migration (41). While it is claimed that rat VSMC migration may be mediated by Il-6-induced Stat 3 activation, supporting evidence has been inconsistent, including only a 2-fold increase in p-Stat3 levels following Il-6 VSMC stimulation (41) and putative Il-6 pathway (JAK2) inhibition causing only very modest attenuation of p-Stat 3 levels (42). In direct opposition and suggesting a species-specific response, human VSMCs express only scant amounts of Il-6 receptor and are intrinsically unresponsive to Il-6 (43). Regardless of these controversies, our mouse models suggest Il-6/gp130 signaling does not regulate VSMC Rantes transcription but rather that this is Tnf- $\alpha$ mediated. This VSMC pathway of Tnf- $\alpha$-stimulated Rantes production is reliant on both p65 and Stat 3 signaling. Furthermore, we did not identify any classic Stat3-binding motifs within the Rantes promoter, thus reinforcing the role of Stat 3 as a transcriptional cofactor involved with p65 binding at NF- $\mathrm{KB}$-binding sites in this pathway. Adding

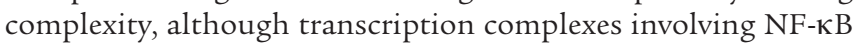
and Stat 3 in liver- and kidney-derived cells have been described, these complexes were inducible in response to Il-6 and/or Il-1 (16, 44). In contrast, our ChIP data suggest increased p65/Stat 3 coas- 

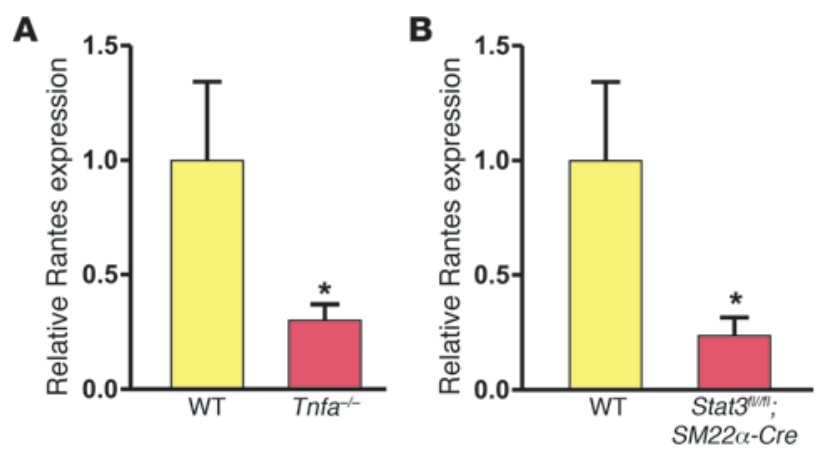

\section{Figure 8}

Vascular Rantes expression is dependent on Tnf- $\alpha$ and Stat3 in vivo. (A) Rantes mRNA expression 6 hours after injury was decreased in femoral arteries from $\mathrm{Tnfa}^{-/}$compared with WT mice ( $n=5$ for WT, $n=8$ for $\mathrm{Tnfa}^{-/}{ }^{-}$; $P<0.05$ ). (B) Rantes mRNA expression 6 hours after injury was decreased in femoral arteries from Stat $3^{f / f t} ; S M 22 \alpha-C r e$ compared with WT mice ( $n=5$ for WT, $n=6$ for Stat $3^{\text {fl/fli; }}$ SM22 $\alpha$-Cre; $\left.{ }^{\star} P<0.05\right)$. Data are shown as mean + SEM.

sociation in response to Tnf- $\alpha$. Therefore, based on our findings, we propose that stimulation of VSMCs by Tnf- $\alpha$ appears to lead to parallel but convergent activation of both the NF- $\kappa B$ and Stat 3 signaling pathways, culminating in Rantes transcription. While the mechanisms of Tnf- $\alpha$-mediated activation of NF- $\kappa \mathrm{B}$ signaling are complex and beyond the scope of this discussion (45), in the case of VSMC Stat 3 activation, we speculate that ligand binding to Tnf- $\alpha-\mathrm{R} 1$, which itself is devoid of intrinsic tyrosine kinase activity, recruits constitutively active nonreceptor tyrosine kinases JAK2 and c-Src to the intracellular Tnf- $\alpha-\mathrm{R} 1$ domain, culminating in Stat3 phosphorylation (46).

An interesting question raised by our work is why Tnf- $\alpha$, rather than Il-6, is so dominant at achieving acute Stat 3 activation and Rantes production in VSMCs. While we did not directly address this question experimentally, our data suggest that Tnf- $\alpha$ is at least partially responsible in vivo for stimulating acute Rantes production by VSMCs following arterial injury. This hypothesis is supported by the fact that local (including local vascular) Tnf- $\alpha$ levels are known to increase dramatically very early after an appropriate stimulus (47) - leading to the original classification of Tnf- $\alpha$ as an "immediate-early" gene (48). Our observation that acute Rantes production by VSMCs is governed by Tnf- $\alpha$ is consistent with an immediate-early local increase in Tnf- $\alpha$ following vascular injury, which may arise from several sources, including adherent monocytes (47) and platelets (49). Conversely, as compared with Tnf- $\alpha$, Il- 6 levels potentially fluctuate over a slower time course (43), with Il-6-dependent VSMC activation reliant on complex activation pathways involving exogenous soluble Il-6 receptor (43). Indeed, the fact that relevant Il-6/gp130 signaling pathways operate with slower kinetics than Tnf- $\alpha$-related pathways, at least in VSMCs, was evidenced in our studies of Stat activation following VSMC stimulation with these cytokines (Figure 7C). Furthermore, Il- 6 has been suggested to be of minimal importance during the acute vascular inflammatory response (50), and although controversial, evidence from $\mathrm{Il}^{-/-}$mice indicates that Il-6 may play a protective role against atherosclerotic plaque progression (51). Therefore, our findings that Tnf- $\alpha$ (rather than Il-6) induces early Stat 3 activation and VSMC Rantes production are consistent with our current conceptual understanding of the pathobiology of acute vascular injury and these signaling systems.

A theoretical criticism of our work is that possible contributions from platelet-derived Rantes were not considered. Indeed, plateletderived Rantes and heteromers between Rantes and other chemokines may be deposited on endothelium, leading to mononuclear cell infiltration $(14,23,52)$. However, although platelet contributions were not directly measured, the fact that $\mathrm{T}$ cell recruitment was dramatically attenuated with local but not BM depletion of Rantes strongly suggests that platelet contributions to vessel Rantes levels are functionally minimal in this clinically relevant arterial denudation model.

The acute production of Rantes by medial VSMCs is consistent with the fact that these cells also produce Mcp-1 within hours of vascular injury, with the time course of Mcp-1 production strikingly similar to that of Rantes (4). Consistent with simultaneous Mcp-1 and Rantes production by VSMCs is that, compared with WT to WT, WT to Rantes ${ }^{-/-}$mice exhibited only an approximately $60 \%$ reduction in macrophage recruitment (Figure 3B). Potentially, ongoing but attenuated macrophage recruitment in WT to Rantes $^{-1-}$ mice may be attributable to Mcp-1.

We validated our findings using $p 21^{-/-}$mice, an established model of increased inflammation and neointimal formation after vascular injury $(2,32,33)$. These experiments verified a Tnf- $\alpha-$

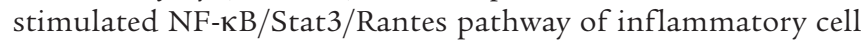
recruitment and shed further light on the orchestration of acute events after arterial injury. While increased p21 $1^{\text {Cip } 1}$ expression has been reported 1 day after arterial injury (33), we identified an even greater increase in $\mathrm{p}^{21^{\mathrm{Cip}} 1}$ at 6 hours after injury, which, based on this and other work (2), appears to limit VSMC cytokine production. Mechanistically, our data suggest that $\mathrm{p} 21^{\text {Cip } 1}$ regulates Rantes by restraining Stat 3 transcription in VSMCs, a finding consistent with reports indicating $\mathrm{p} 21^{\mathrm{Cip} 1}$ inhibits Stat 3 activa-

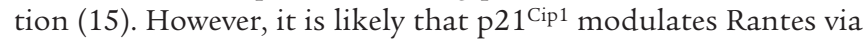
additional pathways. Direct $\mathrm{p} 21^{\mathrm{Cip} 1}$ binding inhibits the activity of several transcription factors including Stat3 (15), c-Myc (53), and E2F (54), and as we show here, in VSMCs, p21 Cip1 complexes with p65 in a Stat3-dependent manner (Figure 5D). Given that p $21^{\text {Cip } 1}$ and Stat 3 also coassociate in VSMCs (2) and again bearing in mind our ChIP data, we speculate that $\mathrm{p}^{21^{\text {Cip }} 1}$ may form a ternary complex with $\mathrm{p} 65$ and Stat3, serving to inhibit the binding and/or transcriptional activity of this complex. Interestingly, the

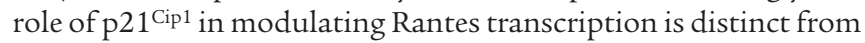
its traditional role as a cell-cycle inhibitor (55). Therefore, while p21 ${ }^{\text {Cip } 1}$ controls cell-cycle progression and restrains VSMC proliferation (2), our data underscore the relatively novel paradigm that p21 $1^{\mathrm{Cip} 1}$ and potentially other members of the cyclin-dependent kinase inhibitor family may additionally function as transcriptional cofactors, being able to both interact directly with DNAbinding proteins and modulate the activity of the coactivators and corepressors that associate with them $(15,56,57)$.

Although not without controversy (58), it is generally accepted that VSMCs express CCR5 (59), a receptor for Rantes. However, CCR5 and CCR1, another Rantes receptor, are widely expressed on T cells, monocytes, and other inflammatory cells $(58,60)$. Adding complexity, both CCR5 and CCR1 also act as receptors for other ligands (27). While VSMCs may migrate in response to Rantes (22), the receptor or receptors responsible for this are unclear, as CCR1 or CCR5 antagonism does not affect VSMC migration or proliferation (31). In the vasculature, despite an initial contrary report (61), 
compared with $\mathrm{Crr}^{+/+}$Apoe ${ }^{-/-}$Cos, CCR5-deficient Apoe $e^{-/-}$mice appear to exhibit decreased atherosclerotic macrophage and $\mathrm{T}$ cell infiltration, decreased plaque area, reduced neointimal formation, and increased VSMC expression of Th2-associated Il-10, an antiinflammatory cytokine $(30,31)$. Paradoxically, genetic deletion of CCR1 in Apoe $e^{-/}$mice may increase T cell infiltration and plaque deposition via enhanced production of proinflammatory and Th1-associated IFN- $\gamma(30,31)$. Nevertheless, systemic treatment with Met-Rantes, a Rantes receptor antagonist with affinity for CCR5 and CCR1 (27), led to reduced macrophage infiltration and decreased neointimal formation in wire-injured arteries of Apoe $e^{-/-}$ mice (14). Likewise, in $\mathrm{Ldlr}^{-/}$mice, systemic Met-Rantes administration reduced atherosclerotic plaque burden, increased plaque stability, and decreased T cell (83\%) and macrophage (43\%) infiltration (27) - results highly concordant with our experiments (Figure $3, \mathrm{~A}$ and $\mathrm{B})$. These findings have also been broadly replicated using a novel Rantes antagonist $\left[{ }^{44} \mathrm{AANA}{ }^{47}\right]$-Rantes (26). Furthermore, this latter study suggested that despite differences between the CCR5 and CCR1 response, antagonism of Rantes signaling is associated with reduced proinflammatory Th1 activity (26). Clinically, controversy exists regarding possible associations between serum RANTES levels and the presence of coronary artery disease $(62,63)$. However, individuals carrying a 32-bp CCR5 deletional mutation, CCR5 $\Delta 32$, appear at reduced risk for cardiovascular disease (64). In summary, converging lines of evidence attest to the importance of Rantes signaling in vascular biology and strongly support the further study and clinical investigation of this pathway.

In conclusion, we examined acute events following arterial wire injury, identifying NF- $\mathrm{KB} /$ Stat3/Rantes signaling as a key factor dictating the early vascular inflammatory response program. Of relevance, murine arterial wire injury is analogous to clinical angioplasty and stenting; more than 1,300,000 inpatient angioplasty procedures were performed in 2006 in the United States alone (65). However, due to neointimal hyperplasia, a significant number of patients require repeat intervention. We are optimistic that novel insights into acute vascular injury, such as those presented here, will lead to improved and targeted therapies for the treatment of vascular diseases including atherosclerosis and other related inflammatory pathologies including arteritis, transplant vasculopathy, and pulmonary hypertension.

\section{Methods}

Mice. WT C57BL/6, Rantes ${ }^{-/}$, and $\mathrm{Tnfa}^{-/-}$mice were obtained from Jackson Laboratories. $p 21^{-/-}$mice were provided by T. Jacks (Massachusetts Institute of Technology, Cambridge, Massachusetts, USA) (2). Stat $3 f / f l$; SM22 $\alpha$-Cre mice were derived by crossing $S M 22 \alpha$-Cre mice (66) into Stat $3^{f / f l}$ mice (67), producing mice with tamoxifen-inducible knockdown of Stat 3 in tissues expressing SM22 $\alpha$ (smooth muscle cells) at the time of tamoxifen treatment. Stat $3^{\ell / f l} ; S M 22 \alpha$-Cre mice were induced by intraperitoneal tamoxifen injection, $1 \mathrm{mg} / \mathrm{d}$ (in $0.1 \mathrm{ml}$ volume) for 7 days, followed by a 1-week break, then a second cycle of $1.5 \mathrm{mg} / \mathrm{d}$ for 7 days. Specificity of SM22 $\alpha$-Cre for medial VSMCs was confirmed by crossing SM22 $\alpha$-Cre with R26R-EYFP mice (Jackson Laboratories), demonstrating that approximately $55 \%$ of medial VSMCs activate Cre and express YFP, with negligible YFP expression in other vascular tissues (data not shown). SM22 $\alpha$-Cre mice were provided by R. Feil (Technische Universität München, Munich, Germany), while $S t a t 3^{f l / f l}$ mice were provided by D. Levy (New York University, New York, New York, USA). Genotype was routinely confirmed by PCR of tail DNA using gene-specific probes. All experiments were approved by the National Heart, Lung, and Blood Institute Animal Care and Use Committee.
Bone marrow transplantation. BM was obtained from 8- to 12-week-old male WT and Rantes ${ }^{-/-}$mice after $\mathrm{CO}_{2}$ euthanasia. BM cell suspensions were flushed from femurs and tibias, filtered, and placed on ice. Recipient female mice were lethally irradiated with 9 Gy whole-body irradiation, with $5 \times 10^{6}$ unfractionated (male) BM cells then delivered by tail-vein injection. Successful engraftment was confirmed, prior to further experimentation, 10 weeks later by qRT-PCR for the presence or absence of Sry to distinguish female and male BM cells (primer sequences provided in Supplemental Methods).

Arterial wire injury, vessel fixation, and vessel harvest. Mice underwent femoral artery wire injury at 12-16 weeks of age or 20-24 weeks of age for BM transplanted mice, as previously described $(2,68)$, resulting in complete endothelial denudation. The surgeon was blinded to mouse genotype. For vessel harvesting, after humane euthanasia, the thorax was entered and the heart swiftly exposed. A generous rent in the right atrium was created. The left ventricle was punctured using a 20-gauge needle, and $20 \mathrm{ml}$ of $1 \times \mathrm{PBS}$ at $4^{\circ} \mathrm{C}$ was infused at approximately $2.5 \mathrm{ml} / \mathrm{min}$. This procedure minimized intraluminal platelet and leukocyte content of harvested vessels, which may have confounded our results. Three methods of vessel harvesting were then used: (a) for PCR and VSMC outgrowth studies vessels were harvested directly, with no further manipulation other than dissection and removal. (b) For vessels intended for immunofluorescence staining, following PBS infusion, $20 \mathrm{ml}$ of $1.5 \%$ paraformaldehyde plus $0.1 \%$ glutaraldehyde in $1 \times \mathrm{PBS}$ at $4{ }^{\circ} \mathrm{C}$ was infused at the same rate (69). Vessels were then harvested and placed in $20 \%$ sucrose in $1 \times \mathrm{PBS}$ at $4^{\circ} \mathrm{C}$ overnight. The next day, vessels were embedded in OCT compound, prepared as fresh frozen slides (10- $\mu \mathrm{m}$-thick sections), and stored at $-80^{\circ} \mathrm{C}$ pending analysis. (c) For neointimal assessment, following PBS infusion, mice were perfused with $20 \mathrm{ml}$ of $10 \%$ neutral buffered formalin at the same rate. Vessels were then harvested and placed in fresh $10 \%$ neutral buffered formalin overnight and transferred to $70 \%$ ethanol the following morning. Vessels were then embedded in paraffin, mounted on slides (5- $\mu \mathrm{m}$-thick sections), and stained with H\&E. Neointima was assessed as previously described $(1,2)$.

VSMCs. Cultured VSMCs were maintained in DMEM containing high glucose, L-glutamine, and sodium pyruvate (GIBCO 11995; Invitrogen) to which $10 \%$ FBS, 100 units/ml penicillin-streptomycin, and additional L-glutamine to a final concentration of $6 \mathrm{mM}$ were added. This medium is henceforth referred to as complete DMEM. Primary VSMCs were obtained by outgrowth methods. In brief, aortas were harvested from 10- to 12-weekold WT and $p 21^{-/-}$mice. Aortas were minced and incubated in $1 \mathrm{mg} / \mathrm{ml}$ type 1A collagenase and $0.125 \mathrm{mg} / \mathrm{ml}$ elastase (C2674 and E0127 respectively; Sigma-Aldrich) in complete DMEM for 15 minutes at $37^{\circ} \mathrm{C}$ with gentle shaking. Tissue fragments were centrifuged, resuspended in complete DMEM, plated, and allowed to adhere. Cells were split after VSMC outgrowth occurred and maintained in complete DMEM. VSMCs used for all experiments were passage 6 to 10 .

Tissue culture. VSMCs were plated at a density of $8.0 \times 10^{3} \mathrm{cells} / \mathrm{cm}^{2}$ for WT and $4.0 \times 10^{3} \mathrm{cells} / \mathrm{cm}^{2}$ for $p 21^{-/-}$to account for the greater rate of $p 21^{-/-}$ VSMC proliferation (2). For Rantes and Stat 3 expression and secretion experiments, WT and $p 21^{-/-}$VSMCs were grown to confluence. Medium was then aspirated, frozen at $-80^{\circ} \mathrm{C}$, and subsequently processed by Thermo Scientific Inc. using SearchLight chemiluminescence sandwich ELISA to quantitate Rantes protein secretion. VSMCs were also harvested at this time for qRT-PCR. VSMCs were counted by hemocytometer and protein data normalized to cell number.

For stimulation experiments, VSMCs and NIH/3T3 cells (CRL-1658; ATCC) were grown to confluence in complete DMEM and treated with murine Tnf- $\alpha$ or Il-6 (315-01A and 216-16 respectively; Peprotech), each at $50 \mathrm{ng} / \mathrm{ml}$, for 1, 2, 4, or 8 hours. Cells were harvested and lysed in RIPA buffer for WB or harvested for RNA extraction and qRT-PCR. For Tnf- $\alpha$-blocking experiments, confluent VSMCs were pretreated with Tnf- $\alpha-\mathrm{R} 1-$ blocking 
antibody (MAB430; R\&D Systems) for 1 hour at the indicated concentrations. Cells were then stimulated for 1 hour with Tnf- $\alpha(50 \mathrm{ng} / \mathrm{ml})$, after which cells were harvested for WB. For experiments involving shRNA-transduced cell lines, VSMCs were generally cultured as described above, but with the addition of $3 \mu \mathrm{g} / \mathrm{ml}$ puromycin to the culture medium.

Luciferase reporter assay. A pGL2 basic firefly luciferase vector containing the murine Rantes promoter sequence from -979 to +8 was donated by X. Ma (Cornell University, Ithaca, New York, USA) (70). Online promoter analysis using TFSEARCH v1.3 (http://www.cbrc.jp/research/db/TFSEARCH.html)

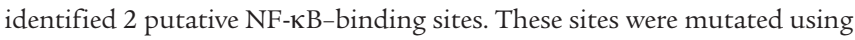
the QuikChange Site-Directed Mutagenesis Kit (Stratagene) with mutation efficacy confirmed using DNA sequencing. Nonmutated, mutated, or pGL2 basic Co plasmids (Promega) were transfected into WT or $p 21^{-/-}$VSMCs using the Basic Nucleofector Kit for Primary Smooth Muscle Cells (Amaxa). VSMCs were also transfected with pRL-SV40 Renilla luciferase vector (Promega) as an internal Co. Each cell group was plated onto culture dishes and harvested after 48 hours, at confluency. Promoter activity was assessed using the Promega Dual-Luciferase Reporter Assay System. Luminescence was measured using a PerkinElmer MicroBeta 1450 JET luminometer.

shRNA knockdown. Stat3, p65, and gp130 were knocked down using Expression Arrest lentiviral shRNA from Open Biosystems. HEK293T cells (Open Biosystems) were transfected with lentiviral shRNA against Stat3 (RMM3981-97059843, clone ID TRCN0000071456), p65 (RMM39819622545, clone ID TRCN0000055346), gp130 (RMM3981-97053778, clone ID TRCN0000065391), or GFP (RHS4459). VSMCs were plated and infected with lentiviral shRNA after 24 hours while subconfluent. Six days after transduction, medium was replaced with complete DMEM containing $3 \mu \mathrm{g} / \mathrm{ml}$ puromycin to select for successful transduction, with cells maintained in this medium from this point forward. Knockdown efficacy was assessed by qRT-PCR and WB.

qRT-PCR. RNA was extracted from cultured VSMCs using the RNeasy Mini Kit (QIAGEN), while RNA from vessels was extracted by pulverizing femoral artery sections with a motorized pestle in TRIzoL Reagent (Invitrogen) according to the manufacturer's instructions. RNA was reverse transcribed using $1 \mu \mathrm{g}$ total RNA by annealing to random primers at $48^{\circ} \mathrm{C}$ in $100 \mu \mathrm{l}$ total reaction volume using TaqMan Reverse Transcription Reagents (N8080234; Applied Biosystems). RNA expression levels were analyzed by qRT-PCR using iQ SYBR Green Supermix (Bio-Rad). A $2 \mu \mathrm{l}$ volume from each cDNA synthesis (cDNA from $20 \mathrm{ng}$ of total RNA) and primers at a final concentration of $0.625 \mu \mathrm{M}$ were combined in a $20-\mu \mathrm{l}$ reaction volume (primer sequences provided in Supplemental Methods). qRT-PCR was performed on an MJ Research Dyad Disciple thermal cycler with Chromo 4 fluorescence detector (Bio-Rad) by denaturation at $95^{\circ} \mathrm{C}$ for 10 minutes, followed by 40 amplification cycles as follows: 10 seconds at $95^{\circ} \mathrm{C}, 20$ seconds at $57^{\circ} \mathrm{C}$, and 30 seconds at $72^{\circ} \mathrm{C}$. Data were analyzed using Bio-Rad MJOpticon Monitor v3.1 software. qRT-PCR results were confirmed by melting temperature analysis, with cDNA product size verified by electrophoresis on $1.25 \%$ agarose gels. cDNA sample quantifications were normalized to $18 \mathrm{~S}$ RNA expression.

Immunofluorescence staining. Immunofluorescence staining was performed on fresh frozen slides with primary antibodies against p65 (ab7970; Abcam), Stat3 (4904; Cell Signaling Technologies), and $\left(\mathrm{Tyr}^{705}\right)$ p-Stat3 (9131; Cell Signaling Technologies), all at 1:50 dilution, and against Rantes (MAB478, R\&D Systems), CD115 (14-1152; eBioscience), and CD3 (ab5690; Abcam) at 1:100 dilution. Co slides were routinely stained in parallel by substituting the primary antibody for IgG or specific IgG isotypes from the same species and at the same final concentration as the primary antibody. Secondary antibodies were donkey anti-rat or -rabbit Alexa Fluor 488 (A-21208 and A-21206, respectively; Invitrogen) at 1:500 dilution or donkey anti-rat or -rabbit Rhodamine Red-X (712-295-150 and 711-295-152, respectively; Jack- son ImmunoResearch Laboratories) at 1:200 dilution. Mounting medium containing DAPI (H-1200; Vector Laboratories) was then applied. Images were acquired using a Zeiss Axioskop plus light microscope with AxioVision V4.3 software, or a Zeiss LSM 510 UV laser scanning confocal microscope system (Carl Zeiss GmbH). All immunofluorescence staining was performed at least 8 times and using sections obtained from differing vessels $/$ mice. Cell counting was performed by a blinded member of our laboratory with extensive experience in cell morphology and the techniques described above.

WBs. Bradford assay was used to determine protein concentration, and $50 \mu \mathrm{g}$ of total protein was loaded into each sample well. Antibodies against p21 Cip1 (556431; BD Biosciences - Pharmingen), p-Stat3 (9145; Cell Signaling Technologies), Stat3 (9139; Cell Signaling Technologies), or p65 (ab7090; Abcam) were used at 1:1000 dilution. Antibody against $\beta$-actin (A3854; Sigma-Aldrich) was used at 1:200,000 dilution. For IP, cells were lysed in NP40 buffer $(75 \mathrm{mM} \mathrm{NaCl}, 1.0 \% \mathrm{NP} 40,50 \mathrm{mM}$ Tris [pH 8.0], protease inhibitors), and $200 \mu \mathrm{g}$ of cell lysate was incubated with the indicated antibodies and/or isotype Co IgG and analyzed by WB.

Quantitative chromatin IP. Formalin cross-linked protein-DNA complexes in cell and tissue lysates were sonicated to an average size of approximately $500 \mathrm{bp}$. Complexes were precleared and IP using protein A sepharose beads (Invitrogen) and antibodies against Stat3 (sc-482; Santa Cruz Biotechnology Inc.), p65 (ab7970; Abcam), or isotype Cos. Subsequently, cross-linking was reversed by overnight incubation at $65^{\circ} \mathrm{C}$ and proteinase $\mathrm{K}$ treatment. Enriched specific promoter fragments were measured by qRT-PCR (primer sequences provided in Supplemental Methods). Relative Stat3 and p65 promoter occupancy were adjusted to the background content of the unrelated $\beta$-actin promoter sequence, isotype IgG Cos, and the initial sonicated chromatin input.

Statistics. For cell culture, each individual experiment was repeated at least 3 times. Experimental data were analyzed by unpaired 2-tailed Student's $t$ test or ANOVA followed by Neuman-Keuls multiple comparison test. Results are expressed as mean \pm SEM. Differences were deemed significant at $P<0.05$. Statistical analyses were performed using Prism, version 4.00 (GraphPad Software).

\section{Acknowledgments}

We thank T. Jacks for providing $p 21^{-/-}$mice, R. Feil for SM22 $\alpha$-Cre mice, and D. Levy for Stat $3^{f l f l}$ mice. We also thank X. Ma for sharing reagents. We thank the staff of the Laboratory of Animal Medicine and Surgery facility and Robin Schwartzbeck for assistance with the transgenic mice. We also acknowledge the professional skills and advice of Christian A. Combs and Daniela Malide (Light Microscopy Core Facility, National Heart, Lung and Blood Institute, NIH), J. Philip McCoy (Flow Cytometry Core Facility, National Heart, Lung and Blood Institute, NIH), and Michelle Olive (Genome Technology Branch, National Human Genome Research Institute). This project was funded by the intramural research program of the National Heart, Lung and Blood Institute. R. Gupta and A. Lee were supported by the Howard Hughes Medical Institute-NIH Research Scholars Program. F. Fang is supported by the Chinese Embassy of Washington, DC, and The Central South University, Changsha, China.

Received for publication July 1, 2009, and accepted in revised form October 7, 2009.

Address correspondence to: Manfred Boehm, Building 10-CRC, Room 5-3132, Translational Medicine Branch, National Heart, Lung, and Blood Institute, National Institutes of Health, Bethesda, Maryland 20892, USA. Phone: (301) 435-7211; Fax: (301) 4517090; E-mail: boehmm@nhlbi.nih.gov. 
1. Boehm M, et al. Bone marrow-derived immune cells regulate vascular disease through a $\mathrm{p}^{2} 7^{\mathrm{Kip} 1}$-dependent mechanism. J Clin Invest. 2004;114(3):419-426.

2. Olive $\mathrm{M}$, et al. p21 modulates arterial wound repair through the stromal cell-derived factor-1/CXCR4 axis in mice. J Clin Invest. 2008;118(6):2050-2061.

3. Chen MS, et al. Bare metal stent restenosis is not a benign clinical entity. Am Heart J. 2006; 151(6):1260-1264.

4. Taubman MB, et al. JE mRNA accumulates rapidly in aortic injury and in platelet-derived growth factor-stimulated vascular smooth muscle cells. Circ Res. 1992;70(2):314-325.

5. Schwarz JB, et al. Novel role of the CXC chemokine receptor 3 in inflammatory response to arterial injury: involvement of mTORC1. Circ Res. 2009; 104(2):189-200.

6. Ait-Oufella H, et al. Natural regulatory $\mathrm{T}$ cells control the development of atherosclerosis in mice. Nat Med. 2006;12(2):178-180.

7. Xiong Z, et al. Higher expression of Bax in regulatory $\mathrm{T}$ cells increases vascular inflammation. Front Biosci. 2008;13:7143-7155.

8. Rogers C, Edelman ER, Simon DI. A mAb to the beta2-leukocyte integrin Mac-1 (CD11b/CD18) reduces intimal thickening after angioplasty or stent implantation in rabbits. Proc Natl Acad Sci US A. 1998;95(17):10134-10139.

9. Rogers C, Welt FG, Karnovsky MJ, Edelman ER. Monocyte recruitment and neointimal hyperplasia in rabbits. Coupled inhibitory effects of heparin. Arterioscler Thromb Vasc Biol. 1996;16(10):1312-1318.

10. Schober A, et al. Crucial role of the CCL2/CCR2 axis in neointimal hyperplasia after arterial injury in hyperlipidemic mice involves early monocyte recruitment and CCL2 presentation on platelets. Circ Res. 2004;95(11):1125-1133.

11. Egashira K, et al. Importance of monocyte chemoattractant protein-1 pathway in neointimal hyperplasia after periarterial injury in mice and monkeys. Circ Res. 2002;90(11):1167-1172.

12. An G, et al. P-selectin glycoprotein ligand-1 is highly expressed on Ly-6 $\mathrm{Chi}^{\text {hi }}$ monocytes and a major determinant for Ly-6Chi monocyte recruitment to sites of atherosclerosis in mice. Circulation. 2008; 117(25):3227-3237.

13. Liu P, Patil S, Rojas M, Fong AM, Smyth SS, Patel DD. CX3CR1 deficiency confers protection from intimal hyperplasia after arterial injury. Arterioscler Thromb Vasc Biol. 2006;26(9):2056-2062.

14. Schober A, et al. Deposition of platelet RANTES triggering monocyte recruitment requires $\mathrm{P}$-selectin and is involved in neointima formation after arterial injury. Circulation. 2002;106(12):1523-1529.

15. Coqueret $\mathrm{O}$, Gascan H. Functional interaction of STAT3 transcription factor with the cell cycle inhibitor $\mathrm{p}^{2} 1^{\mathrm{WAF} 1 / \mathrm{CIP} 1 / \mathrm{SDI} 1}$. J Biol Chem. 2000; 275(25):18794-18800.

16. Hagihara K, et al. Essential role of STAT3 in cytokinedriven NF-kappaB-mediated serum amyloid A gene expression. Genes Cells. 2005;10(11):1051-1063.

17. Yang J, et al. Unphosphorylated STAT3 accumulates in response to IL- 6 and activates transcription by binding to NFkappaB. Genes Dev. 2007;21(11):1396-1408.

18. Schmitz ML, Mattioli I, Buss H, Kracht M. NF-kappaB: a multifaceted transcription factor regulated at several levels. Chembiochem. 2004;5(10):1348-1358.

19. Casola A, Henderson A, Liu T, Garofalo RP, Brasier AR. Regulation of RANTES promoter activation in alveolar epithelial cells after cytokine stimulation. Am J Physiol Lung Cell Mol Physiol. 2002;283(6):L1280-1290.

20. Krohn R, et al. Y-box binding protein-1 controls CC chemokine ligand-5 (CCL5) expression in smooth muscle cells and contributes to neointima formation in atherosclerosis-prone mice. Circulation. 2007;116(16):1812-1820.
21. Yun JJ, et al. Rantes production during development of cardiac allograft vasculopathy. Transplantation. 2001;71(11):1649-1656.

22. Bae YS, et al. Macrophages generate reactive oxygen species in response to minimally oxidized lowdensity lipoprotein: toll-like receptor 4- and spleen tyrosine kinase-dependent activation of NADPH oxidase 2. Circ Res. 2009;104(2):210-218.

23. von Hundelshausen $P$, et al. RANTES deposition by platelets triggers monocyte arrest on inflamed and atherosclerotic endothelium. Circulation. 2001;103(13):1772-1777.

24. Schall TJ, Bacon K, Toy KJ, Goeddel DV. Selective attraction of monocytes and $\mathrm{T}$ lymphocytes of the memory phenotype by cytokine RANTES. Nature. 1990;347(6294):669-671.

25. Makino $Y$, et al. Impaired T cell function in RANTESdeficient mice. Clin Immunol. 2002;102(3):302-309.

26. Braunersreuther $V$, et al. A novel RANTES antagonist prevents progression of established atherosclerotic lesions in mice. Arterioscler Thromb Vasc Biol. 2008;28(6):1090-1096.

27. Veillard NR, et al. Antagonism of RANTES receptors reduces atherosclerotic plaque formation in mice. Circ Res. 2004;94(2):253-261.

28. Alam R, et al. Increased MCP-1, RANTES, and MIP1alpha in bronchoalveolar lavage fluid of allergic asthmatic patients. Am J Respir Crit Care Med. 1996;153(4 Pt 1):1398-1404.

29. Boiardi L, et al. Relationship between serum RANTES levels and radiological progression in rheumatoid arthritis patients treated with methotrexate. Clin Exp Rheumatol. 1999;17(4):419-425.

30. Braunersreuther V, et al. Ccr5 but not Ccr1 deficiency reduces development of diet-induced atherosclerosis in mice. Arterioscler Thromb Vasc Biol. 2007;27(2):373-379.

31. Zernecke A, et al. Deficiency in CCR5 but not CCR1 protects against neointima formation in atherosclerosis-prone mice: involvement of IL-10. Blood. 2006;107(11):4240-4243

32. Chang MW, Barr E, Lu MM, Barton K, Leiden JM. Adenovirus-mediated over-expression of the cyclin/ cyclin-dependent kinase inhibitor, p21 inhibits vascular smooth muscle cell proliferation and neointima formation in the rat carotid artery model of balloon angioplasty. J Clin Invest. 1995;96(5):2260-2268.

33. Yang ZY, et al. Role of the p21 cyclin-dependent kinase inhibitor in limiting intimal cell proliferation in response to arterial injury. Proc Natl Acad Sci US A. 1996;93(15):7905-7910.

34. Malik N, et al. Apoptosis and cell proliferation after porcine coronary angioplasty. Circulation. 1998;98(16):1657-1665.

35. Perlman H, Maillard L, Krasinski K, Walsh K. Evidence for the rapid onset of apoptosis in medial smooth muscle cells after balloon injury. Circula tion. 1997;95(4):981-987.

36. Lee AH, Hong JH, Seo YS. Tumour necrosis factoralpha and interferon-gamma synergistically activate the RANTES promoter through nuclear factor kap$\mathrm{paB}$ and interferon regulatory factor 1 (IRF-1) transcription factors. Biochem J. 2000;350(Pt 1):131-138.

37. Bartoli M, et al. VEGF differentially activates STAT3 in microvascular endothelial cells. FASEB J. 2003; 17(11):1562-1564.

38. Hajra L, et al. The NF-kappa B signal transduction pathway in aortic endothelial cells is primed for activation in regions predisposed to atherosclerotic lesion formation. Proc Natl Acad Sci U S A. 2000;97(16):9052-9057.

39. Danenberg HD, et al. Macrophage depletion by clodronate-containing liposomes reduces neointimal formation after balloon injury in rats and rabbits. Circulation. 2002;106(5):599-605.

40. Hoffmann A, Leung TH, Baltimore D. Genetic analysis of NF-kappaB/Rel transcription factors defines functional specificities. EMBO J. 2003;
22(20):5530-5539.

41. Wang D, et al. An essential role for gp130 in neointima formation following arterial injury. Circ Res. 2007;100(6):807-816

42. Watanabe $S$, et al. Role of JAK/STAT pathway in IL-6-induced activation of vascular smooth muscle cells. Am J Nephrol. 2004;24(4):387-392.

43. Klouche M, Bhakdi S, Hemmes M, Rose-John S. Novel path to activation of vascular smooth muscle cells: up-regulation of gp130 creates an autocrine activation loop by IL- 6 and its soluble receptor. J Immunol. 1999;163(8):4583-4589.

44. Yoshida Y, et al. Interleukin 1 activates STAT3/nuclear factor-kappaB cross-talk via a unique TRAF6and p65-dependent mechanism. J Biol Chem. 2004; 279(3):1768-1776.

45. Hayden MS, Ghosh S. Shared principles in NF-kappaB signaling. Cell. 2008;132(3):344-362.

46. Pincheira R, Castro AF, Ozes ON, Idumalla PS, Donner DB. Type $1 \mathrm{TNF}$ receptor forms a complex with and uses Jak2 and c-Src to selectively engage signaling pathways that regulate transcription factor activity. J Immunol. 2008;181(2):1288-1298.

47. Weyrich AS, McIntyre TM, McEver RP, Prescott SM, Zimmerman GA. Monocyte tethering by P-selectin regulates monocyte chemotactic protein-1 and tumor necrosis factor-alpha secretion. Signal integration and NF-kappa B translocation. J Clin Invest. 1995;95(5):2297-2303.

48. Juliano RL, Haskill S. Signal transduction from the extracellular matrix. J Cell Biol. 1993;120(3):577-585.

49. Limb GA, Webster L, Soomro H, Janikoun S, Shilling J. Platelet expression of tumour necrosis factor-alpha (TNF-alpha), TNF receptors and intercellular adhesion molecule-1 (ICAM-1) in patients with proliferative diabetic retinopathy. Clin Exp Immunol. 1999;118(2):213-218.

50. McClintock SD, et al. Role of interleukin- 6 in immune complex induced models of vascular injury. Inflammation. 2005;29(4-6):154-162.

51. Schieffer B, et al. Impact of interleukin- 6 on plaque development and morphology in experimental atherosclerosis. Circulation. 2004;110(22):3493-3500.

52 . Koenen RR, et al. Disrupting functional interactions between platelet chemokines inhibits atherosclerosis in hyperlipidemic mice. Nat Med. 2009; 15(1):97-103

53. Kitaura H, et al. Reciprocal regulation via proteinprotein interaction between c-Myc and $\mathrm{p} 21^{\mathrm{cip} 1 / \text { waf1/sdi1 }}$ in DNA replication and transcription.J Biol Chem. 2000;275(14):10477-10483.

54. Delavaine L, La Thangue NB. Control of E2F activity

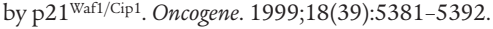

55. Harper JW, Adami GR, Wei N, Keyomarsi K, Elledge SJ. The p21 Cdk-interacting protein Cip1 is a potent inhibitor of G1 cyclin-dependent kinases. Cell. 1993;75(4):805-816.

56. Coqueret $\mathrm{O}$. New roles for p21 and p27 cell-cycle inhibitors: a function for each cell compartment? Trends Cell Biol. 2003;13(2):65-70.

57. Perkins ND. Not just a CDK inhibitor: regulation of transcription by $\mathrm{p}^{2} 1^{\mathrm{WAF} 1 / \mathrm{CIP} 1 / \mathrm{SDI} 1}$. Cell Cycle. 2002;1(1):39-41.

58. Hayes IM, et al. Human vascular smooth muscle cells express receptors for CC chemokines. Arterioscler Thromb Vasc Biol. 1998;18(3):397-403.

59. Schecter AD, et al. Human vascular smooth muscle cells possess functional CCR5. J Biol Chem. 2000; 275(8):5466-5471.

60. Weber C, et al. Specialized roles of the chemokine receptors CCR 1 and CCR5 in the recruitment of monocytes and $\mathrm{T}_{\mathrm{H}} 1$-like/CD45RO ${ }^{+} \mathrm{T}$ cells. Blood. 2001;97(4):1144-1146.

61. Kuziel WA, et al. CCR5 deficiency is not protective in the early stages of atherogenesis in apoE knockout mice. Atherosclerosis. 2003;167(1):25-32.

62. Koh SJ, et al. Association of serum RANTES concentrations with established cardiovascular risk 
markers in middle-aged subjects. Int J Cardiol. 2009;132(1):102-108

63. Rothenbacher D, Muller-Scholze S, Herder C, Koenig W, Kolb H. Differential expression of chemokines, risk of stable coronary heart disease, and correlation with established cardiovascular risk markers. Arterioscler Thromb Vasc Biol. 2006;26(1):194-199.

64. Gonzalez P, et al. Genetic variation at the chemokine receptors CCR5/CCR2 in myocardial infarction. Genes Immun. 2001;2(4):191-195.
65. Lloyd-Jones D, et al. Heart disease and stroke statistics--2009 update: a report from the American Heart Association Statistics Committee and Stroke Statistics Subcommittee. Circulation. 2009; 119(3):e21-e181.

66 . Kuhbandner S, et al. Temporally controlled somatic mutagenesis in smooth muscle. Genesis. 2000; 28(1):15-22.

67. Lee CK, et al. STAT3 is a negative regulator of granulopoiesis but is not required for G-CSF-dependent differentiation. Immunity. 2002;17(1):63-72.
68. Duckers HJ, et al. Heme oxygenase-1 protects against vascular constriction and proliferation. Nat Med. 2001;7(6):693-698.

69. Brazelton TR, Blau HM. Optimizing techniques for tracking transplanted stem cells in vivo. Stem Cells. 2005;23(9):1251-1265.

70. Liu J, Guan X, Ma X. Interferon regulatory factor 1 is an essential and direct transcriptional activator for interferon $\gamma$-induced RANTES/CCl5 expression in macrophages. J Biol Chem. 2005; 280(26):24347-24355. 